\title{
Therapeutics
}

\section{The addition of folic acid to fluoxetine for major depression increased response rates especially in women}

Coppen A, Bailey J. Enhancement of the antidepressant action of fluoxetine by folic acid: a randomised, placebo controlled trial.J Affect Disord 2000 Nov;60:121-30.

QUESTION: In patients with major depression, does the addition of folic acid to fluoxetine increase the antidepressant effect?

\section{Design}

Randomised (allocation concealed*), blinded (unclear)*, placebo controlled trial with 10 weeks of follow up.

\section{Setting}

Centres where 19 general practitioners and 1 consultant psychiatrist worked.

\section{Patients}

127 patients who were $\geqslant 18$ years of age (mean age 43 y); had a new episode of depression (first depressive episode in the previous 6 months); met DSM-III-R criteria for major depressive disorder; scored $\geqslant 20$ on the 17 item Hamilton Depression Rating Scale (HDRS); did not use folic acid or antidepressants in the previous 9 weeks; and did not have contraindications to fluoxetine. $86 \%$ of patients ( $63 \%$ women) completed the study.

\section{Intervention}

After stratification by sex, patients were allocated to fluoxetine, $20 \mathrm{mg} /$ day, plus folic acid, $500 \mu \mathrm{g} /$ day $(\mathrm{n}=62)$, or to fluoxetine, $20 \mathrm{mg} /$ day, plus placebo $(\mathrm{n}=65)$.

\section{Main outcome measures}

Clinical response ( $>50 \%$ improvement on the HDRS).

\section{Main results}

More patients in the folic acid group than in the placebo group had $>50 \%$ improvement on the HDRS $(\mathrm{p}<0.05)$ (table). A statistically significant interaction existed for sex $\{p=0.02\} \uparrow$. When results were analysed separately for men and women, the difference remained for women $(94 \%$ for fluoxetine $v 61 \%$ for placebo, $\mathrm{p}<0.005$ ) but not for men.

\section{Conclusions}

In patients with major depression, the addition of folic acid to fluoxetine increased the response rate. An interaction between sex and response rate existed: the treatment effect was seen in women but not in men.

*See glossary.

$\dagger p$ Value calculated from data in article.
Fluoxetine plus folic acid v fluoxetine plus placebo for major depression

\begin{tabular}{lcccc} 
Outcome at 10 weeks & Folic acid & Placebo & RBI (95\% Cl) & NNT (CI) \\
$\begin{array}{l}\text { Response rate } \\
(>50 \% \text { improvement on HDRS })\end{array}$ & $82 \%$ & $62 \%$ & $33 \%(5$ to 71$)$ & $5(3$ to 30$)$ \\
\hline $\begin{array}{l}\ddagger \text { HDRS=Hamilton Depression Rating Scale. Other abbreviations defined in glossary; RBI, NNT, and Cl calculated } \\
\text { from data in article. }\end{array}$
\end{tabular}

\section{COMMENTARY}

The findings of the study by Coppen and Bailey are of great potential significance for the treatment of depression. They rest upon the old observation that plasma and red cell folate concentrations are reduced in major depression. These deficiencies may be correctable by simple dietary supplementation with the vitamin. The observation reported is that such supplementation improves the response of patients treated with fluoxetine in general practice. The prospect of an inexpensive and non-toxic intervention that would have even a modest effect upon response to a common and disabling disorder such as major depression is an extremely compelling one. If correct, this result should change clinical practice. Will it?

The study was randomised, placebo controlled, and allocation concealment was achieved using a centralised computer system. The primary outcome measure was a $>50 \%$ improvement in score on the HDRS. As with many clinical trials in psychiatry, the major limitation was size, and size matters. 127 patients were originally randomised, of whom 18 dropped out. There was a marginal net effect on response rates for all completing patients. This was actually an effect in women only, however. No effect occurred in men, which parallels the absence of an effect on folate/ homocysteine biochemistry. The findings would be weakened by the inclusion of dropouts but would still remain of considerable interest.

Nevertheless, in the absence of a major marketing exercise (which is unlikely to occur for a non-patentable product), clinicians are unlikely to be much influenced by this result. The problem with this study is that it is, quite simply, too small. A much bigger study is highly feasible. What would be desirable, however, is greater simplicity and preferably more compelling clinical or economic outcomes than simply the improvement in scores on a rating scale. It represents a further challenge in psychiatry to shift the evidence base from small scale, hypothesis generating studies of this sort to large scale studies of efficacy and effectiveness that will change practice and usher in a new era of more effective treatment based on reliable evidence.

Guy M Goodwin, DPhil, FRCP, FRCPsych Warneford Hospital Oxford, UK
Source of funding: Scotia

Pharmaceuticals.

For correspondence: Dr A Coppen, 5 Walnut Close, Downs Road, Epsom, Surrey +44(0)1372742602. KT18 5JL, UK. Fax 